Article

\title{
4R-Cembranoid Treatment Alters Gene Expression of RAW264.7 Macrophages in Basal and Inflammatory Conditions
}

Maxine N. Gonzalez-Vega ${ }^{1,2}$, Sandeep Sreerama2, Kelvin Carrasquillo-Carrion ${ }^{3}$, Abiel Roche ${ }^{3}$, Susan Corey Best ${ }^{5}$, Kiminobu Sugaya ${ }^{2}$, Pedro A. Ferchmin ${ }^{4}$, Vesna A. Eterovic $^{4}$, Antonio H. Martins ${ }^{5^{*}}$

1. Universidad Central del Caribe, Neuroscience Department; Ave. Laurel \#100, Santa Juanita, Bayamón, P.R., 00956. Tel: (787) 798-3001

2. University of Central Florida, Burnett School of Medicine; 6900 Lake Nona Blvd, Orlando, FL 32827. Tel: (407) 266-7045

3. University of Puerto Rico, Medical Sciences Campus, Biomedical Data Science Department; Guillermo Arbona Irizarry Bld, San Juan, P.R. 00936-5067. Tel: (787) 758-2525 Ext. 2194

4. Universidad Central del Caribe, Biochemistry Department; Ave. Laurel \#100, Santa Juanita, Bayamón, P.R., 00956. Tel: (787) 798-3001

5. University of Puerto Rico, Medical Sciences Campus, Pharmacology and Toxicology Department; Calle Los Paseos, Guillermo Arbona Bldg, San Juan, PR 00935. Tel: (787) 758-2525 Ext. 1300 or 1304.

${ }^{*}$ Author to whom correspondence should be addressed:

Dr. Antonio H. Martins; Tel.787-758-2525, Fax: 787-766-4441;

antonio.martins@upr.edu

Abstract: Inflammation is considered an important target for stroke therapy because it induces secondary brain damage after the initial ischemic insult. Peripheral monocytes migrate to the brain parenchyma after a central insult. They then differentiate to macrophages in a positive feedback fashion contributing to damage instead of ischemic resolution and inflammation control. A cyclic diterpenoid, (1S,2E,4R,6R,7E,11E)-cembra-2,7,11-triene-4,6-diol

decreases neurodegeneration after ischemia with central anti-inflammatory activity. This study aims to determine whether the central anti-inflammatory effect of $4 R$ is effective against peripheral inflammation triggered by brain ischemia. To investigate the anti-inflammatory effect of $4 R$, we treated macrophages with lipopolysaccharide (LPS) as an inflammatory model, followed by treatment with 4 R. Microarray transcriptome analysis of over 30,000 genes identified the differential expression of 393 genes. Genes related to inflammation, cell adhesion, and 
transcription were validated with $\mathrm{qPCR}$, and reduced expression was determined. Quantification of NF-kB phosphorylation served as a marker for the modulation of inflammation through gene transcription. Our results show that $4 \mathrm{R}$ was associated with a reduction in NFKB1 and ITGB5 gene expression, increased phosphorylation of NF-kB, and a decrease in macrophage adhesion in a blood-brain barrier model. These results indicate that $4 \mathrm{R}$ can partially modulate the peripheral immune response, making $4 \mathrm{R}$ a potential drug against post-ischemic inflammation.

Keywords: cembranoid; inflammation; macrophage, NF-kB, adhesion

\section{Introduction}

Stroke is medically defined as a disease that affects arteries conducting to or in the brain, affecting the proper supply of blood. It is the second leading cause of death and adult disability worldwide [1]. Neuronal death initiates glutamate excitotoxicity that causes a toxic effect on the surrounding tissue, propagating an inflammatory signaling cascade responsible for increasing the ischemic damage caused by stroke [2-5]. A few days after the initiation of ischemia, brain inflammation causes the recruitment of peripheral monocytes, which are responsible for regulating the transition from acute inflammation to chronic inflammation [6]. The inflammatory factors produced by macrophages influence the activation, migration, and effector function of partner inflammatory cells by changing the inflammatory response, either in the resolution of inflammation or the propagation of tissue damage [7]. Macrophages are essential producers of cytokines, chemokines, and adhesion molecules, as well as other inflammatory factors that are critical signaling mechanisms for host defense from pathogenic infection to traumatic injuries [8].

Unfortunately, effective drugs that target chronic inflammation in the central nervous system (CNS) have not yet been discovered. Therefore, there is an urgent need to identify new safe molecules that can modulate central inflammation after an ischemic insult. Peripheral immunity depends on a set of signaling and adhesion 
molecules such as integrins and cell adhesion molecules (CAMs) that permit the infiltration of macrophages into the affected tissue.

A cyclic diterpenoid, (1S,2E,4R,6R,7E,11E)-cembra-2,7,11-triene-4,6-diol, termed 4R, has been found to provide CNS protection in neurodegenerative diseases $[9,10]$ and exposure to an analog of sarin, the neurotoxic gas [11]. Moreover, 4R has been shown to decrease expression of intercellular adhesion molecule 1 (iCAM-1) and vascular cell adhesion molecule 1 (vCAM-1) in a murine brain-derived endothelial cell line, bEND5, that serves as a blood-brain barrier model under normal and pathologic conditions such as stroke, Parkinson's disease, and inflammation [9,10]. The direct central neuroprotection and decreased reactivity of astrocytes, which can be considered a decrease of inflammation [12], provided by $4 \mathrm{R}$ is triggered by processes that involve the Akt pathway [11]; however, little is known about the modulatory mechanisms of peripheral inflammation.

Olsson (1993) reported that $4 \mathrm{R}$ inhibits prostaglandin synthesis in seminal bovine microbiomes with an $\mathrm{IC}_{50}$ of $390 \mu \mathrm{M}$ [13], supporting the notion that $4 \mathrm{R}$ possesses the capacity of modulating inflammation. These changes in the inflammatory microenvironment will influence the activation of astrocytes, as well as the recruitment of the peripheral immune system. In this study, we examine the peripheral inflammatory modulatory capacity of $4 \mathrm{R}$ and its role in the adhesion of macrophages to human brain microvascular cells, a model of the blood-brain barrier, thus expanding and reproducing its effect in bEND5 endothelial cells [9].

\section{Materials and Methods}

\subsection{Cell Cultures and Maintenance Reagents}

\subsubsection{RAW264.7 Cells}


The murine macrophage cell line RAW264.7 was obtained from the American Type Cell Culture (ATCC, Virginia, USA, cat. \#TIB-71) and cultured in complete DMEM (cDMEM) [10\% FBS, 100 units/mL of Penicillin and 100 $\mu \mathrm{g} / \mathrm{mL}$ streptomycin), 1\% non-essential amino acids (100x, Thermo Fisher formulation) and 2mM L-glutamine] and maintained at $37^{\circ} \mathrm{C}$ with $5 \% \mathrm{CO}_{2}$. The medium was changed every 2-3 days, and cells were passed using a cell scraper before they reached 95\% confluence. For experiments, 2x106 RAW264.7 cells were plated in $60 \mathrm{~mm}$ tissue culture-treated dishes and left overnight to recover. Macrophages were treated with $5 \mu \mathrm{M}$ of $4 \mathrm{R}$ (stock 20mM), $0.025 \%$ polyethylene glycol/ ethanol at a ratio of $90 \% / 10 \% \mathrm{v} / \mathrm{v}$, respectively (PEG/Eth ), and/or 100ng/mL LPS (stock 0.1mg/mL).

\subsection{2 hCMEC/D3 cells}

Immortalized human cerebral microvascular endothelial cells (hCMEC/D3) were purchased from Millipore Sigma (Darmstadt, Germany, cat. \#SCC066). Cells were cultured to confluence in EBM-2 basal medium (Lonza) supplemented with a proprietary formulation MV-Bullet Kit from Lonza [for 500mL final volume, FBS (12.5mL), R3-IGF-1 (125 $\mu \mathrm{L})$, VEGF $(125 \mu \mathrm{L})$, human EGF $(125 \mu \mathrm{L})$, hydrocortisone $(50 \mu \mathrm{L})$, human bFGF $(5 \mu \mathrm{L})]$, and 100 units $/ \mathrm{mL}$ of penicillin and $100 \mu \mathrm{g} / \mathrm{mL}$ streptomycin. Cultured cells were maintained at $37^{\circ} \mathrm{C}$ with $5 \% \mathrm{CO}_{2}$, changing the media every 2-3 days, and sub-cultivating every five days. For experiments, $2 \times 10^{5}$ hCMEC/D3 cells were seeded in a 24-well tissue culture treated-plate and maintained for $24 \mathrm{hrs}$ to allow monolayer formation.

\subsection{Comprehensive transcriptome analysis}


The murine macrophage cell line, RAW264.7, was plated at $2 \times 10^{6}$ cells per dish (60 $\mathrm{mm}$ tissue culture-treated dishes). Once flasks reached $90 \%$ confluence, the cells were treated with 100ng/mL LPS in fresh cDMEM for 2hrs (see flowchart, Fig. 1). Then the cells were washed with cDMEM twice and treated with $5 \mu \mathrm{M} 4 \mathrm{R}$ or vehicle (0.025\% PEG/Eth) for $1 \mathrm{hr}$. The treatment was followed by two washes with cDMEM, and cells were left to rest for 2hrs in fresh cDMEM, allowing time to respond to the given stimuli. After treatment, cells were collected using the cell-scrapper and pelleted by centrifugation at $500 \times \mathrm{g}$ for 10 minutes. The cell pellet was stored at $80^{\circ} \mathrm{C}$. Samples were processed for comprehensive transcriptome analysis at the University of Puerto Rico Medical Sciences Campus (San Juan, PR, Core Facility) using the GeneChip WT Pico Kit (902622; Affymetrix) and the GeneChip Mouse Transcriptome Pico Assay 1.0 (902663; Affymetrix).

\subsection{Ingenuity Pathway Analysis (IPA)}

For the analytical section, data processing and differential expression analysis were performed using the Bioconductor software packages oligo and limma. The microarray raw intensity values were processed in the Affymetrix CEL file format using the Robust Multi-array Average (RMA) algorithm from the oligo package. Background correction was done, $\log 2$ transformed and normalized by quantile normalization. The statistical analysis was conducted using the limma software package. Case versus control group analysis was performed with the following data sets, with three replicates per group: $4 \mathrm{R}$ vs. PEG/Eth, and [4R with LPS] vs. [PEG/Eth with LPS]. Differentially expressed genes were defined as having a Fold-Change (FC) $\geq 2$ and $p$-value $\leq 0.05$ ). The differentially expressed genes for both comparisons were 
submitted for Ingenuity Pathway Analysis of Apoptosis-, Proliferation-, and Inflammation-related pathways and networks.
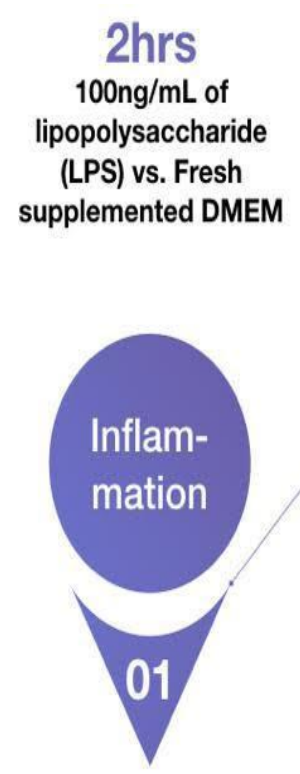

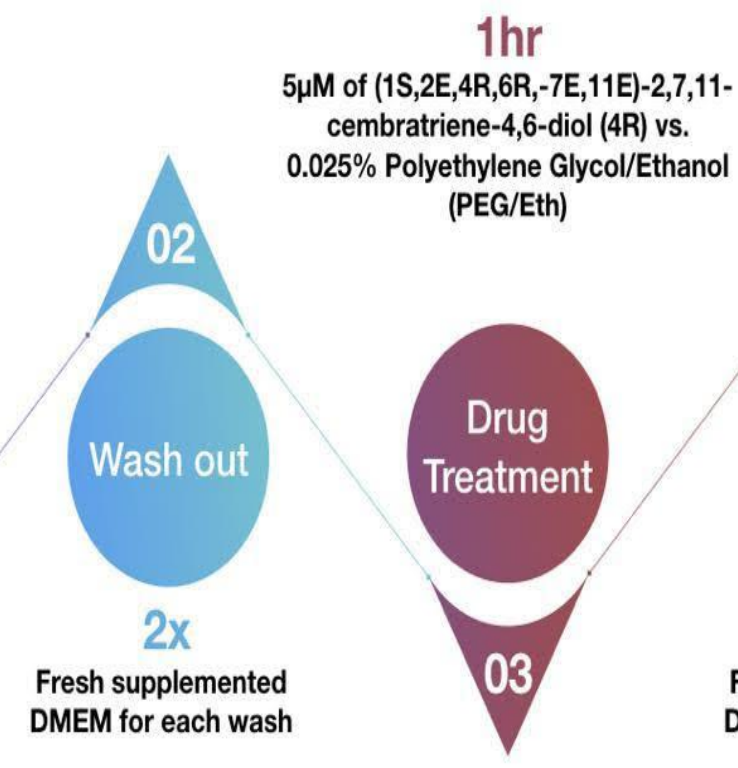

\section{$1 \mathrm{hr}$} cembratriene-4,6-diol (4R) vs. $0.025 \%$ Polyethylene Glycol/Ethanol (PEG/Eth)

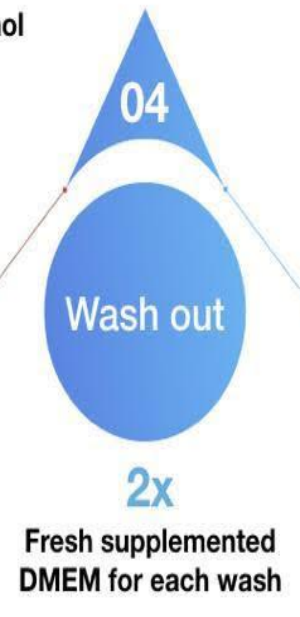

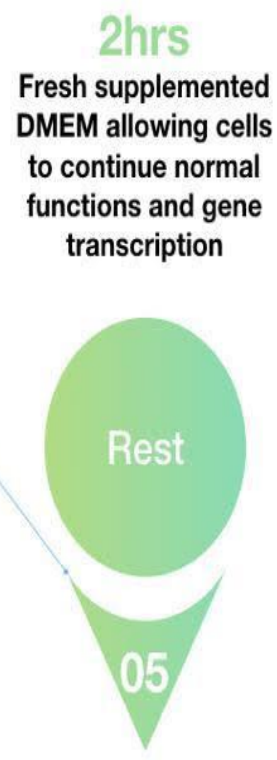

Figure 1. Timeline for treatment of RAW264.7 cells with 4R and/or LPS for transcriptome analysis.

\subsection{Real-time quantitative PCR}

Total RNA was isolated from samples treated according to the LPS \pm 4 R microarray timeline (Fig. 1) and the 6hrs simultaneous treatments in RAW264.7 macrophage cells. Macrophages were treated for 6hrs continuously with the drug compound or vehicle in the presence and absence of LPS. RNA was isolated using the Direct-zol RNA MiniPrep (Zymo Research), treated in the column with DNAse I, and RNA quality was determined with a NanoDrop ${ }^{\mathrm{TM}} 8000$ Spectrophotometer (Thermo Scientific). In total, $1.0 \mu \mathrm{g}$ of RNA were reverse-transcribed into cDNA using a SuperScript III First-Strand Synthesis SuperMix qRT-PCR (Invitrogen). Real-time quantitative PCR was performed in a 7500 Fast Real-Time PCR System (Life Technologies) for IL-1 $\beta$, NFKBIE, NFKB1, CCL5, ITGB5, iCAM, MCP-1, iNOS, and $\beta$-Actin targets. Primers (Table 1) were purchased from Eurofins Genomics. 
Quantitative PCR was performed in duplicates in a total volume of $20 \mu \mathrm{L}$ containing 100ng of RNA reverse-transcribed to cDNA, 10 $\mu \mathrm{L}$ of SYBR Green PCR Master Mix (Applied Biosystems), and 300nM primer concentration. Cycling conditions for the quantitative RT-PCRs were as follows: $95^{\circ} \mathrm{C}$ for $10 \mathrm{~min}$, followed by 40 cycles at $95^{\circ} \mathrm{C}$ for 15 seconds and $60^{\circ} \mathrm{C}$ for 60 seconds. Analysis of the melting curves demonstrated that each pair of primers amplified a single product. Relative changes in mRNA expression for the genes were assessed by the $2^{-\Delta \Delta \mathrm{Ct}}$ method using the corresponding mRNA expression for vehicle-treated samples (PEG/Eth, and LPS+PEG/Eth) as a calibrator (set to a value of 1). Samples were classified into two groups of basal and LPS stimulation, and then an unpaired t-test was performed for the samples for each gene and group using Prism7.

Table 1. Primers used for qRT-PCR analysis.

\begin{tabular}{|c|c|c|c|c|c|}
\hline Gene & Forward $\left(5^{\prime} \rightarrow 3^{\prime}\right)$ & Reverse $\left(5^{\prime} \rightarrow 3^{\prime}\right)$ & Accession Num. & $\begin{array}{c}\text { Reference or } \\
\text { Primer Bank ID }\end{array}$ & $\begin{array}{l}\text { Product } \\
\text { Size }\end{array}$ \\
\hline ILlBeta & GСААСТGТTССТСААСТСААСТ & ATCTTTTGGGGTCCGTCAACT & NM_008361.4 & Tomita et al., 2016 & 89 \\
\hline $\mathrm{MCPl}$ & TGATCCCAATGAGTAGGCTGGAG & ATGTCTGGACCCATTCCTTCTTG & NM_011333.3 & Diamond et al., 2007 & 132 \\
\hline iNOS & TTCACCCAGTTGTGCATCGACCTA & TCCATGGTCACCTCCAACACAAGA & NM_001313922.1 & Tomita et al., 2016 & 140 \\
\hline iCAMl & CAATTTCTCATGCCGCACAG & AGCTGGAAGATCGAAAGTCC & NM_010493.3 & Ren et al., 2010 & 103 \\
\hline NFKBIE & TGGACCTCCAACTGAAGAACT & TTCCTCTGCAATGTGGCAATG & NM_008690.4 & 3154332lal & 64 \\
\hline NFKBl & ATGGCAGACGATGATCCCTAC & TGTTGACAGTGGTATTTCTGGTG & NM_008689.2 & 30047197al & 111 \\
\hline ITGB5 & GAAGTGCCACCTCGTGTGAA & GGACCGTGGATTGCCAAAGT & NM_001145884 & $225007620 \mathrm{cl}$ & 86 \\
\hline CCL5 & GCTGCTTTGCCTACСTCTCC & TCGAGTGACAAACACGACTGC & NM_013653.3 & 730546lal & 104 \\
\hline GAPDH & СТСССАСТСТТССАССТТС & GCCTCTCTTGCTCAGTGTCC & NM_001289726.1 & Ruiz-Villalba et al., 2017 & 189 \\
\hline
\end{tabular}

\subsection{Immunoblotting}


RAW264.7 cells previously treated with LPS \pm 4 R for 1 hr (see Fig. 1) were washed twice with PBS and collected by scraping with a cell scraper, while immersed in $1 \mathrm{~mL}$ of PBS to avoid cell-damage. The cells were pelleted by centrifugation at $300 \times \mathrm{g}$ for 10 minutes, then resuspended in ice-cold M-Per lysis buffer (Thermo Scientific) supplemented with protease and phosphatase inhibitor cocktail (2mM 4Benzenesulfonyl fluoride hydrochloride, $0.3 \mu \mathrm{M}$ Aprotinin, $130 \mu \mathrm{M}$ Bestatin, $1 \mathrm{mM}$ EDTA, $14 \mu \mathrm{M}$ E-64 and $1 \mu \mathrm{M}$ leupeptin) (Sigma-Aldrich) and allowed to rest for 20 mins. With 2 minutes intervals, samples were vortexed for 10 sec. The cell-debris pellet was collected by centrifuging the cells at $16.3 \times 10^{3} \mathrm{x}$ g at $4^{\circ} \mathrm{C}$ for 10 minutes; the supernatant was collected, and the insoluble pellet was discarded. Total protein was measured using the BCA assay (Pierce Thermo Scientific). From the cell lysates, 15 $\mathrm{gg}$ of total protein in NuPAGE LDS buffer and reducing agent was heated at $70^{\circ} \mathrm{C}$ for 10 minutes and cooled on ice for 5 minutes. The proteins were separated on $10 \%$ NuPAGE SDS-polyacrylamide gel (Invitrogen) together with PageRuler Plus prestained protein ladder (Thermo Scientific) and transferred to a nitrocellulose membrane 0.45 $\mathrm{mm}$ (Schleicher \& Schuell; Grade BA85). After blocking with 5\% nonfat milk in Tris-buffered saline, 0.1\% Tween-20 (TBST) for $1 \mathrm{hr}$ at room temperature $\left(23^{\circ} \mathrm{C}\right)$, the membranes were incubated with specific antibodies overnight at $4^{\circ} \mathrm{C}$. The following primary antibodies were purchased from Cell

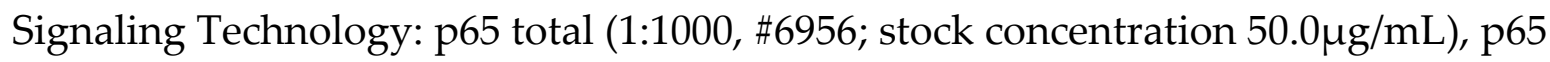

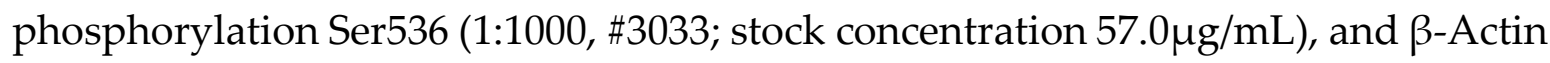
(1:5000, \#4970; stock concentration $116.0 \mu \mathrm{g} / \mathrm{mL})$. HRP-conjugated secondary antibodies (Cell Signaling Technology) were used at a 1:5000 dilution (stock concentration $0.8 \mathrm{mg} / \mathrm{mL}$ ). The antigen-antibody complexes were visualized using the enhanced chemiluminescence West Femto Detection System (Thermo Fisher) according to the manufacturer's protocol. ImageJ software was used to detect the intensity value reading for each sample within the sample blot. Using Prism7 
samples were classified and divided into groups of basal drug treatment and LPSstimulated macrophages, then an unpaired t-test performed detected any changes in protein intensity.

\subsection{Adhesion Assay}

The hCMECD3 human cerebral microvascular endothelial cells were incubated for 24hrs with 100ng/mL LPS incubation. After 24hrs, 4R $(5 \mu \mathrm{M})$ or PEG/Eth $(0.025 \%)$ was added for the remaining $24 \mathrm{hrs}$ period. The $4 \mathrm{R}$-treated cells were stained with

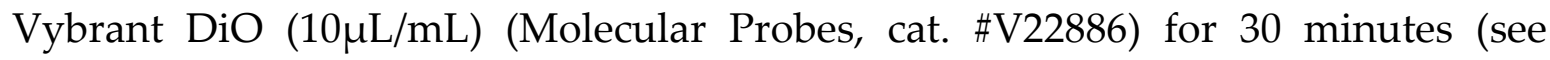
Timeline, Fig. 2). The hCMECD3 monolayer cells were washed three times with PBS, and $1 \times 10^{6} \mathrm{DiI}^{+}$stained RAW264.7 macrophages (pre-stained with $0.3 \mathrm{mg} / \mathrm{mL} \mathrm{DiI}{ }^{+}$for 1hr, Molecular Probes, cat. \#D282) were added to the monolayer and maintained for 1 hr at $37^{\circ} \mathrm{C}$ with $5 \% \mathrm{CO}_{2}$. Cells were washed three times with PBS to remove any non-adherent macrophages and fixed with $1 \mathrm{~mL}$ of $4 \%$ paraformaldehyde/PBS with subsequent incubation for 20 minutes at $4^{\circ} \mathrm{C}$. Using 1x Phosphate Buffer Saline (PBS, $\mathrm{pH} 7.4)$, cells were washed twice and counterstained for cell nuclei using DAPI (4',6diamidino-2-phenylindole) at a concentration of $1 \mu \mathrm{g} / \mathrm{mL}$ for 10 minutes. Microscopy data were collected from a minimum of four fields of view per sample (12 fields of view in total for each treatment), done in biological triplicate. Images were taken using Zeiss 710 with the Zeiss AxioObserver microscope (lens: LD Plan Neofluar 20x/0,4 Ph2 Korr 421351-9970) and analyzed using ImageJ cell count. 


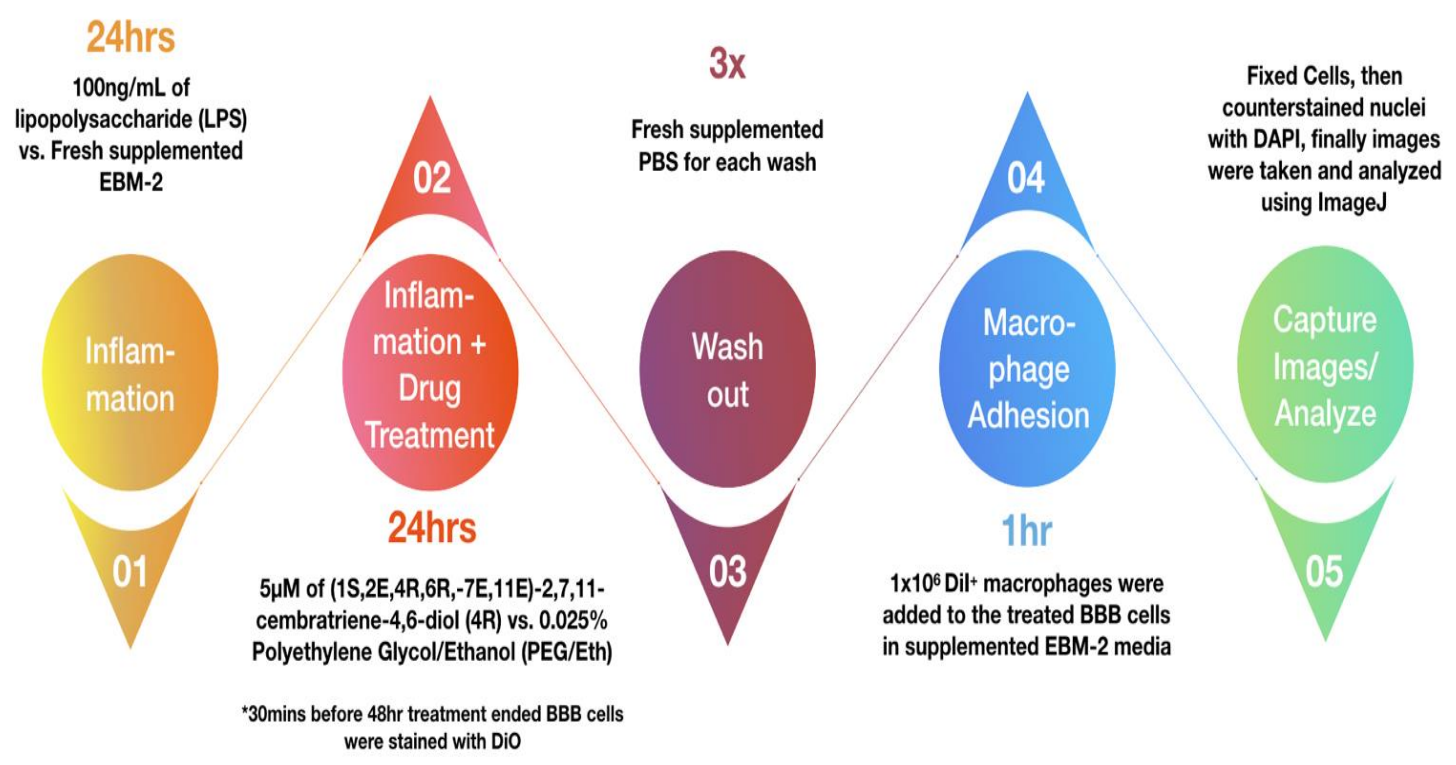

Figure 2. Timeline of LPS $\pm 4 R$ treatment for adhesion assay.

\section{Results}

$3.14 R$ treatment alters gene expression in murine macrophages responsible for canonical pathways involved in inflammation and cell survival.

Treatment with $4 \mathrm{R}$ after inflammatory treatment with LPS regulates an array of genes involved in mediating select cell responses, including inflammation, viral protection, and proliferation when compared to the vehicle groups, PEG/Eth, or LPS + PEG/Eth. A total of 393 genes (302 up-regulated and 91 down-regulated) were identified and color-coded in a volcano plot (Fig. 3A-B). Genes that were not regulated by $4 \mathrm{R}$ treatment are shown in black, and these are considered natural variation within cell samples and not due to the treatments.

Of the 302 genes that were upregulated, 33\% are associated with inflammation, implying activation of the pathways involved. Of the 91 down-regulated genes, $86 \%$ 
are involved in cell cycle function. Canonical pathways regulated by $4 \mathrm{R}$ (Fig. 3C) include DNA replication (22 genes), NF-kB (18 genes), Toll-like Receptor Signaling (13 genes), IL-6 Signaling (13 genes), Interferon (12 genes), TNF- $\alpha$ (12 genes), Apoptosis (10 genes), ERK/MAPK (7 genes), Cytokine-Cytokine Receptor Interaction (7 genes), G2/M DNA Damage Checkpoint Regulator (5 genes) and Cytokine Signaling (4 genes). Genes involved in inflammation and cell cycle were selected to compare expression under normal and inflammatory conditions after $4 \mathrm{R}$ treatment (Fig. 3D). For most of the selected genes, $4 \mathrm{R}$ treatment under basal conditions appeared to decrease the expression of inflammatory genes (IL1A, RSAD2, and CCL5), and up-regulate genes involved in macrophage differentiation and cell migration (CXCR4 and S1PR1, respectively). Specific fold changes for selected genes are shown in Table 2. Notably, post-inflammatory 4R-treatment upregulated genes involved in inflammatory responses in peripheral macrophages after LPS. However, this did not translate into the propagation of cell damage in previously published in vivo experiments [9-11,14,15]. The post-inflammatory response to $4 \mathrm{R}$ could mean that $4 \mathrm{R}$ modulates inflammation in a manner that provides additional immediate support, but not prolonged enough to produce damage. Also, it strongly suggests that the inflammatory mechanism of action is through a signaling pathway that includes NF-kB.

3.2 qPCR validation of select microarray genes, determined a modulation of $i N O S, N F K B 1$, ITGB5, and IL-1Beta in murine macrophage cells treated with $4 R$ on basal and LPS conditions 
Under basal conditions (Fig. 1), 4R did not significantly alter expression of IL-1Beta, NFKBIE, NFKB1, iNOS, CCL5, ITGB5, ICAM1, and MCP1 (FC= 1.34 $\pm 0.19,1.17 \pm 0.1$, $1.08 \pm 0.17,1.77 \pm 0.16,0.82 \pm 0.09,1.1 \pm 0.12,1.02 \pm 0.04$, and $0.96 \pm 0.12$, respectively, mean \pm SEM ). Similar mRNA expression patterns were observed for most genes for the $4 \mathrm{R}$ group when compared to the vehicle group (Figs. 3A and $4 \mathbf{A}$ ). Only iNOS expression was up-regulated 2-fold by $4 \mathrm{R}$ treatment for $1 \mathrm{hr}$ (Fig. 5A). Induction of mRNA for all genes was evident after LPS stimulation for $2 \mathrm{hrs}$ before drug treatment when compared to basal conditions (Table S1-S2). Post-4R treatment to LPS stimulated macrophages decreased the mRNA of NFKB1 and ITGB5 (FC $=0.72 \pm 0.029$, and $0.77 \pm 0.01$, respectively, mean \pm SEM) (Fig. 4B). There was no difference between $4 \mathrm{R}$ and PEG/Eth controls in the expression patterns of IL-1Beta, NFKBIE, iNOS, CCL5, ICAM1, and MCP1 mRNA after LPS treatment (Fig. 4B): (FC=0.98 \pm 0.07 , $1.17 \pm 0.10,0.71 \pm 0.13,0.87 \pm 0.06,0.81 \pm 0.09$, and $1.22 \pm 0.14$, mean $\pm S E M$ respectively) . 
A.

\section{Differentially Expressed Genes by 4R Treatment}

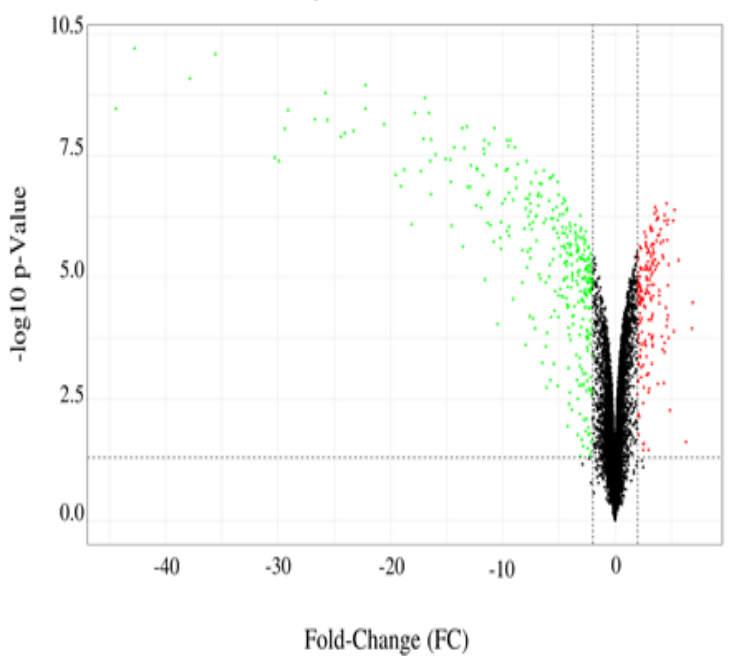

C.

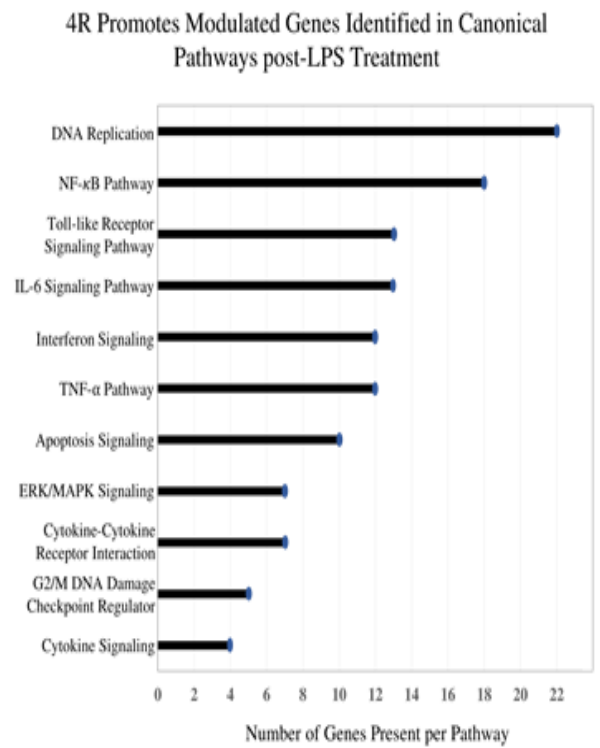

\section{Post-Inflammatory 4R Treatment Differentially}

B. Expressed Genes Compared to Vehicle Treated Group

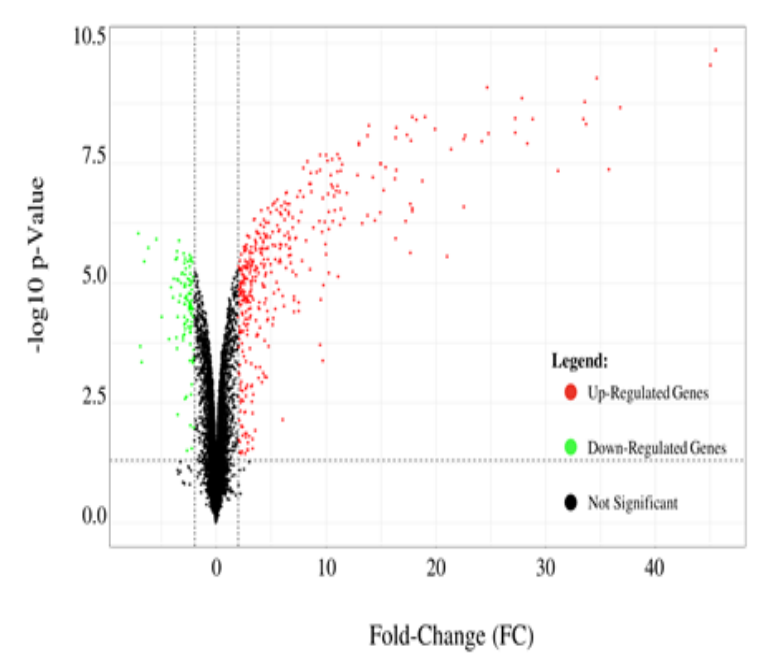

D. Selection of Genes Modulated by Post-LPS 4R Treatment

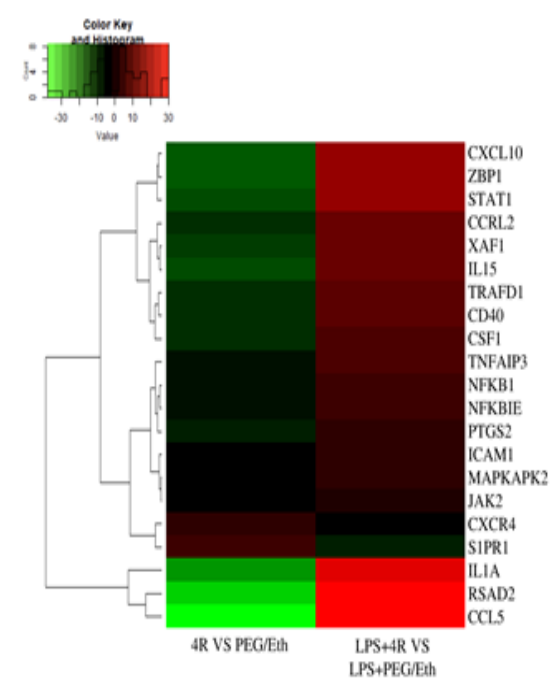

Figure 3. $4 \mathrm{R}$ treatment modulates under basal and inflammatory conditions the expression of key genes in RAW264.7 macrophages. A, B. Volcano maps of gene expression fold changes. Plots of fold changes versus significance (-log $\mathrm{P}$ value) in macrophages. Down-regulated genes are represented by green dots, up-regulated genes by red dots, and un-regulated genes by black dots. The horizontal line represents $\mathrm{p}<0.05$, and the two vertical lines represent \pm 2 -fold change. A. Fold changes in macrophages treated with $4 \mathrm{R}$ versus vehicle-only. B. Fold changes in macrophages treated with $\mathrm{LPS} \pm 4 \mathrm{R}$. C. Classification of selected genes modulated by $4 \mathrm{R}$ that are involved in canonical pathways of inflammation and cell viability. Most of the genes are associated with DNA replication or the NF- $\kappa B$ pathway. D. A heat map of selected fold changes in two conditions, $4 \mathrm{R}$ vs control in basal conditions and $4 \mathrm{R}$ vs vehicle after LPS. Green represents down-regulation (-FC), red represents the up-regulation of gene expression, and black represents no significant change. 
Table 3.2. Genes in the Heatmap plot. Genes found in the heatmap plot with the fold change for each cluster (4R vs PEG/Eth and LPS+4R vs LPS+PEG/Eth). Genes selected were based on those found in the canonical pathways studied. ${ }^{*}$ gene not found in the heatmap.

\begin{tabular}{|c|c|c|}
\hline & \multicolumn{2}{|c|}{ G ene Fold $-C$ hange $(p<=0.05)$} \\
\hline Gene Name & 4R vs PEG/Eth & LPS+4R vs LPS+PEG/Eth \\
\hline CCL2 & -11.32 & 15.27 \\
\hline CCRL2 & -9.59 & 11.89 \\
\hline CCL5 & -37.77 & 33.67 \\
\hline CD 40 & -9.43 & 8.54 \\
\hline CSF1 & -8.025 & 7.09 \\
\hline CXCL10 & -14.54 & 17.87 \\
\hline CXCR4 & 2.50 & -3.67 \\
\hline$I C A M 1$ & -2.36 & 3.17 \\
\hline $\mathbb{L} 1 \mathrm{~A}$ & -22.16 & 27.89 \\
\hline $\mathbb{L} 1 B$ & -30.23 & 33.50 \\
\hline $\mathbb{L} 15$ & -11.91 & 11.67 \\
\hline $\operatorname{ITG} B 5 *$ & 3.00 & -2.95 \\
\hline A $K 2$ & -2.11 & 2.14 \\
\hline M APKAPK2 & -2.27 & 2.31 \\
\hline NFKB1 & -4.45 & 5.17 \\
\hline$N F K B \mathbb{E}$ & -3.88 & 4.31 \\
\hline NOS2 & -4.43 & 4.25 \\
\hline$P T G S 2$ & -5.77 & 3.99 \\
\hline RSAD 2 & -29.91 & 33.75 \\
\hline S1PR1 & 4.28 & -6.15 \\
\hline STAT1 & -12.82 & 16.43 \\
\hline TNFA $\mathbb{P} 3$ & -4.67 & 6.96 \\
\hline TRAFD 1 & -9.57 & 10.02 \\
\hline$X A F 1$ & -11.20 & 5.36 \\
\hline$Z B P 1$ & -14.63 & 16.32 \\
\hline
\end{tabular}


A.
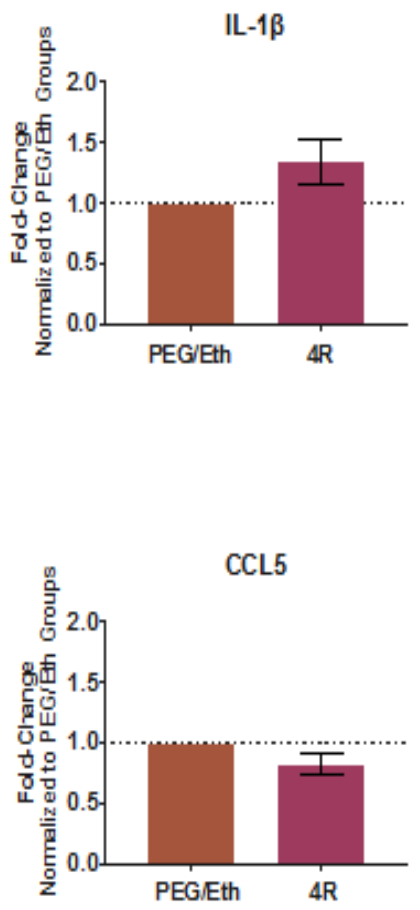

B.
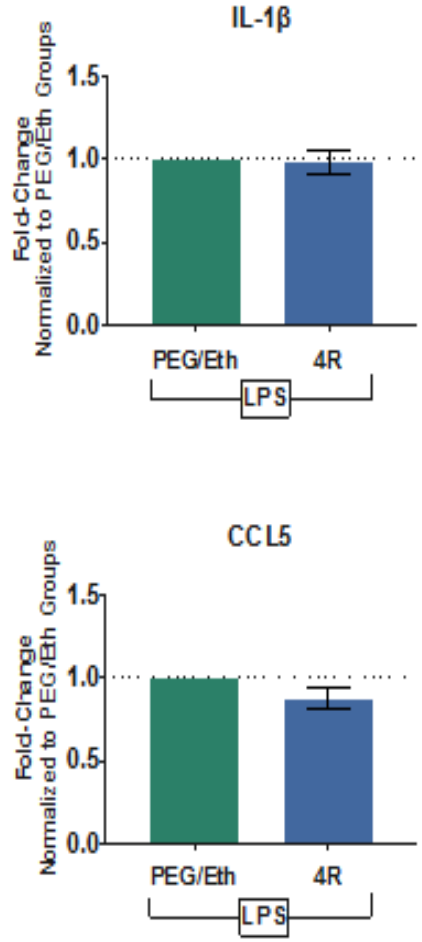

NFKBIE

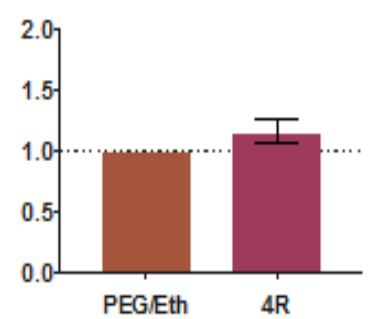

$4 R$
NFKB1

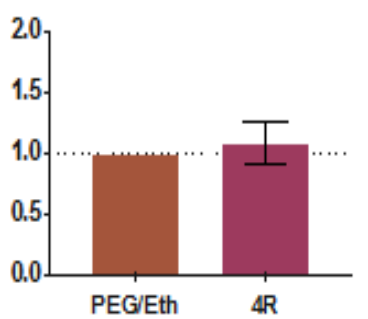

iCAM1

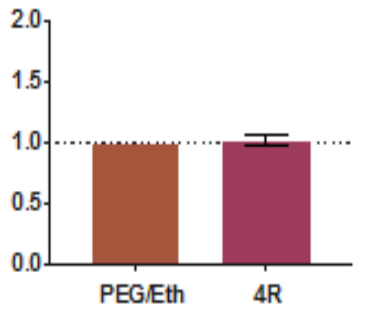

NFKB1

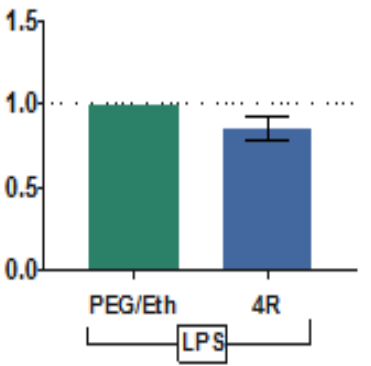

ITGB5
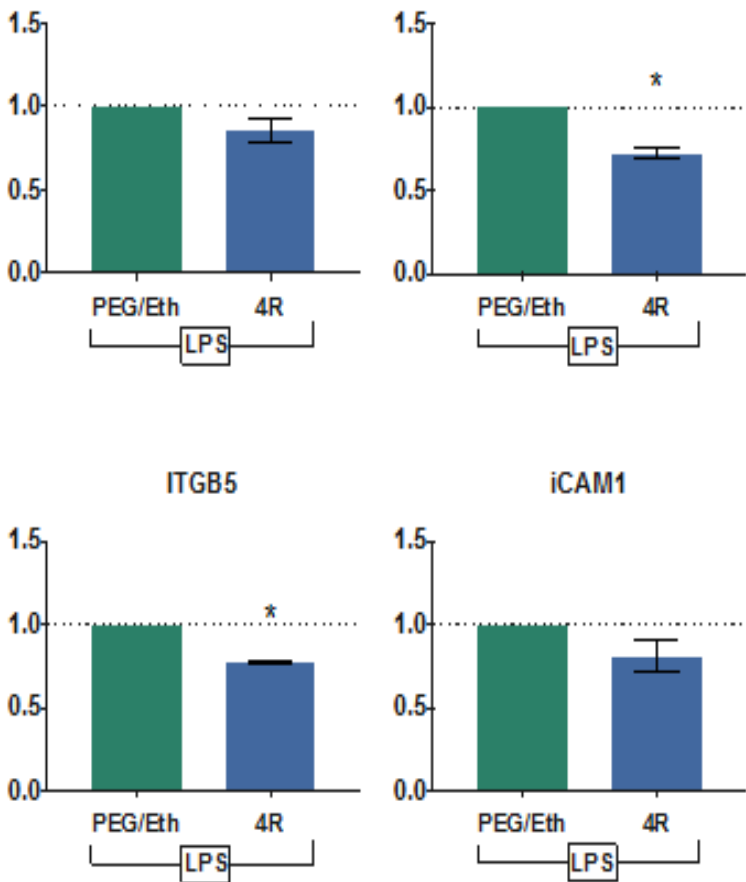

iCAM1

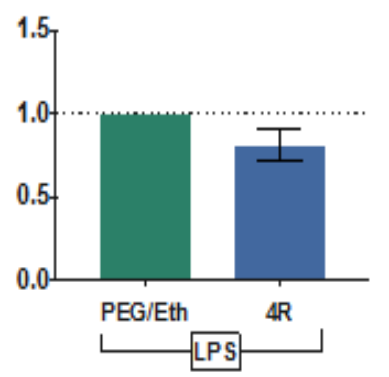

iNOS

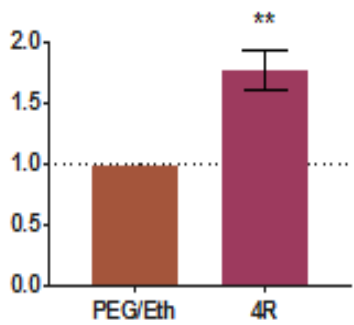

MCP-1

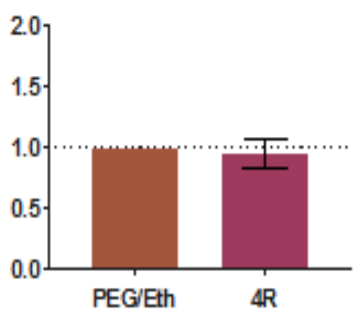

iNOS

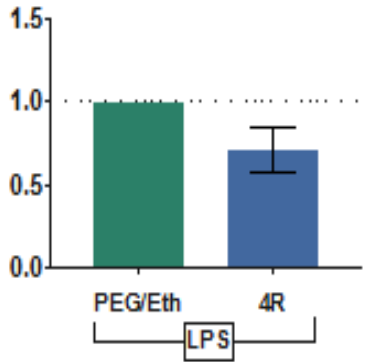

MCP-1

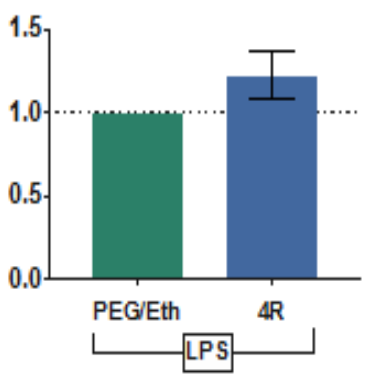

Figure 4. Validation by quantitative PCR of genes identified in Fig. 3 sequential treatment of RAW264.7 macrophages with LPS and 4R (Fig. 1). A. Gene validation for qRT-PCR with vehicle and $4 \mathrm{R}$ treatment for IL-1B, NFKBIE, NFKB1, iNOS, CCL5, ITGB5, iCAM1, and MCP-1. 4R treatment increased iNOS gene expression when compared to PEG/Eth, whereas all other tested genes showed no modulation for basal conditions. B. The same genes validated with the LPS inflammatory insult for both PEG/Eth and 4R: Treatment with $4 \mathrm{R}$ decreased gene expression of NFKB1 and ITGB5. Plot of the mean \pm SEM, statistical analysis used, Unpaired T-Test, ${ }^{*} \mathrm{p}<0.05$, ** $(\mathrm{P}=0.001$ to 0.01$) ; \mathrm{n}=3$ 
A.
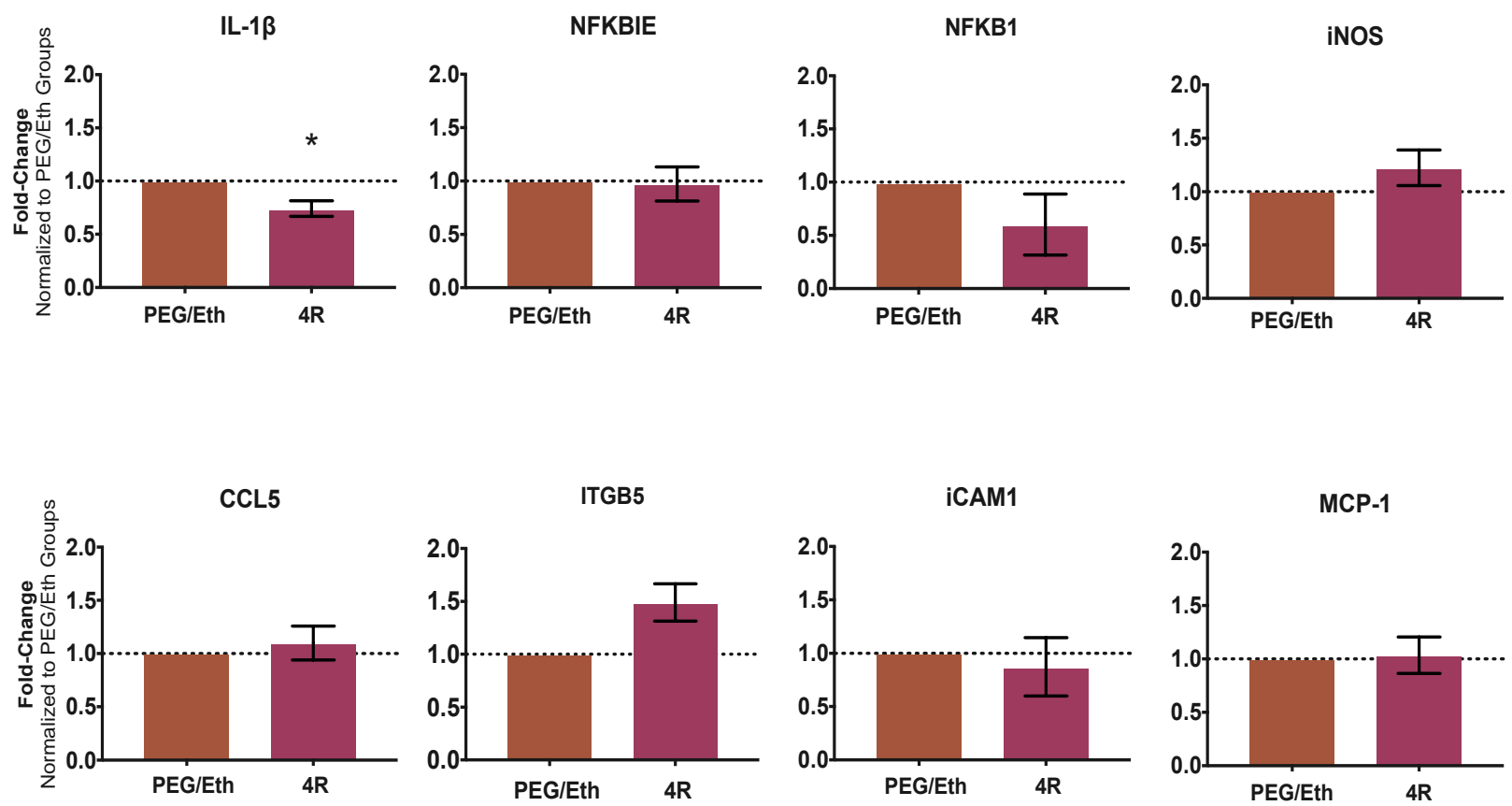

B.
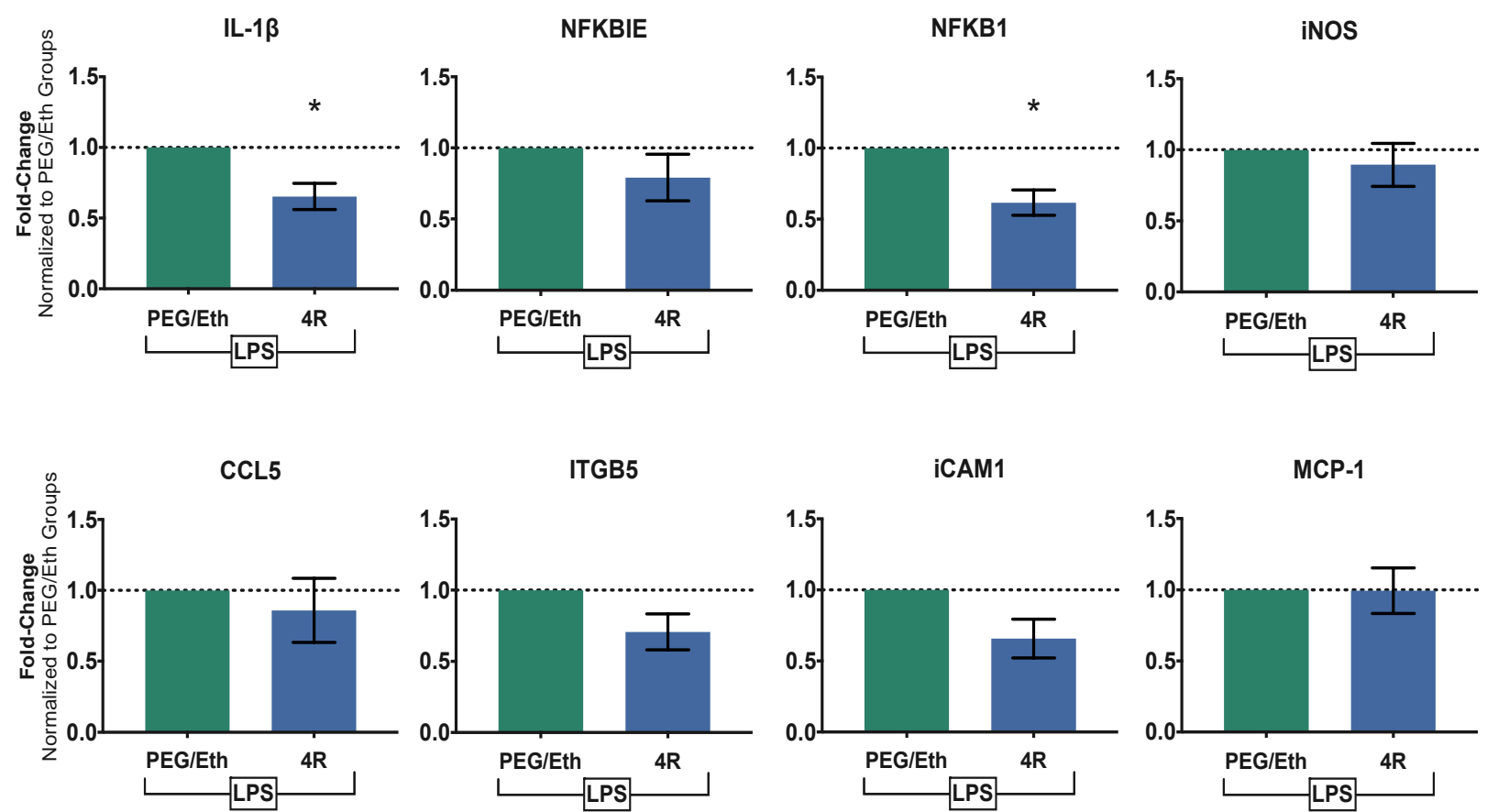

ITGB5

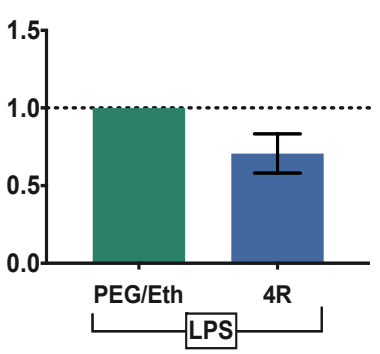

ICAM1

MCP-1
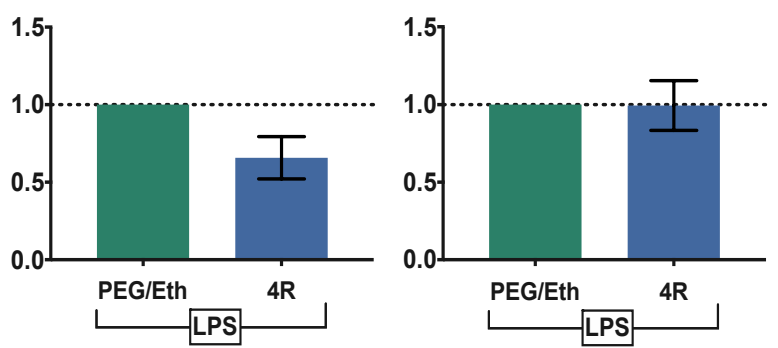

Figure 5. Quantitative PCR of inflammatory genes following 6hrs incubation of macrophages with LPS \pm 4 R. A. Genes tested for validation (IL-1B, NFKBIE, NFKB1, iNOS, CCL5, ITGB5, iCAM1, and MCP-1) were quantified for simultaneous treatment of $4 \mathrm{R}$ or vehicle. Basal $6 \mathrm{hrs}$ treatment of $4 \mathrm{R}$ decreased IL-1B genes when compared to PEG/Eth. All other tested genes showed similar patterns between $4 \mathrm{R}$ and drug vehicle groups. B. The simultaneous $6 \mathrm{hrs}$ treatment with LPS and 4R showed down-regulation of IL-1B and NFKB1 genes. The data presented are mean \pm SEM. Unpaired T-Test, ${ }^{*} \mathrm{p}<0.05 ; \mathrm{n}=3$ 
In contrast, 6 hrs stimulation of macrophages with $4 \mathrm{R}$ alone decreased mRNA of IL1Beta $(F C=0.74 \pm 0.073$, mean \pm SEM) when compared to the PEG/Eth group; the remaining genes showed no differences in mRNA expression (Fig. 5A). Simultaneous incubation with 4 R or vehicle and LPS for 6hrs produced decreases in IL-1Beta and NFKB1 gene expression $(F C=0.65 \pm 0.09,0.62 \pm 0.089$, respectively, mean \pm SEM); no significant differences were found in the expression of mRNA for NFKBIE, iNOS, CCL5, ITGB5, ICAM1, and MCP1 for both LPS+4R and LPS+PEG/Eth groups $(F C=0.97 \pm 0.16,0.92 \pm 0.15,0.86 \pm 0.23,0.71 \pm 0.13,0.66 \pm 0.14$, and 0.99 \pm 0.16 , respectively, mean \pm SEM) (Fig. 5B). A consistent downregulation of NFKB1 mRNA expression was seen in both the microarray timeline protocol (Fig. 1) and the 6hrs simultaneous incubation of macrophages with $4 \mathrm{R}$ or vehicle in the presence of LPS.

3.3 Simultaneous treatment with $4 R$ and LPS promotes an early increase in the activation of NF-kB through the Ser536 phosphorylation of $p 65$

Detecting phosphorylation of p65 at the TAD site indicates that p65 has moved to the nucleus and has begun gene transcription. The expression of phosphorylated Ser536 p65 was not significantly different from vehicle PEG/Eth under basal conditions (p65 Ser536 116.1 $\pm 15.82 \%$, compared to the mean value for PEG/Eth normalized to 100). Stimulation with LPS for $1 \mathrm{hr}$ increased overall protein expression, and co-incubation with $4 \mathrm{R}$ enhanced the increase $(120.7 \pm 7.77 \%$, mean \pm SEM vs. control) (Fig. 6A). Total p65 protein was significantly increased under basal conditions with $4 \mathrm{R}$ treatment for $6 \mathrm{hrs}$ (p65 total $4 \mathrm{R}$ mean \pm SEM, $113.9 \pm 5.003 \%$ ) when compared to the vehicle-treated group. In contrast, total p65 was unchanged when incubated with LPS $\pm 4 R$ or vehicle for 6hrs (total p65 $=106.3 \pm 7.911 \%$ vs. normalized control, mean \pm SEM) (Fig. 6B). The normalized values 
for the p65 Ser536 and p65 total for each treatment were divided to determine the ratio of activation for each treatment. Under basal conditions, $4 \mathrm{R}$ treatment did not modulate the ratio of p65 phosphorylation (p65 ser536/total p65 after 4R, $104.7 \pm 20.72 \%$, mean \pm SEM), but the ratio of phosphorylated ser536 to p65 did increase following LPS stimulation with $4 \mathrm{R}$ treatment for $6 \mathrm{hrs}$ (mean \pm SEM of ratios of normalized values, $126.9 \pm 11.07 \%$ ) (Fig. 6C).

The $4 \mathrm{R}$ compound has been shown to modulate $\alpha 4 \beta 2$ and $\alpha 7$ nicotinic receptors activity [16]; these receptors are known to have a downstream activation effect on p50/p65 activation. Additionally, LPS activates toll-like receptor 4, ultimately activating the NF-kB pathway. Therefore, the simultaneous activation of these pathways may explain the increased expression of the p65 Ser536 phosphorylation in macrophages co-treated with $4 \mathrm{R}$ and LPS (Fig. 6D). Activation of this pathway is known to lead to an inflammatory response of macrophages.

$3.44 R$ decreases the adhesion of peripheral murine macrophages to the hCMEC/D3 cells, a model of the blood-brain barrier (BBB) after $48 \mathrm{hrs}$ of LPS stimulation.

Macrophage cells are key modulators of inflammation in the host. However, when it comes to CNS inflammation, they have to adhere, and then infiltrate the BBB to mediate any injury. Excess peripheral infiltration of macrophages to the CNS will prolong and disseminate damage in the brain. In the presence of an insult, the BBB increases in adherent proteins that act as anchors for peripheral immune cells, and this phenomenon also occurs in macrophages via integrins and cell adhesion molecules [17].

Validated 4R promoted downregulation of ITGB5 for microarray samples, indicates a modulation in macrophage tissue invasion at a genetic phase. To test the functional effect of $4 \mathrm{R}$ on macrophage adhesion, $\mathrm{DiI}^{+}$stained macrophages were exposed to 
hCMEC/D3 cells treated for 48hrs with LPS or left in basal conditions. After the first 24hrs of inflammation insult, $4 \mathrm{R}$ or PEG/Eth was added for the remaining 24hrs (Fig. 7A). Macrophages that remained adhered to hCMEC/D3 after intensive washes were counted, and the overall ratio was determined as adhesion. Basal conditions showed no change in adhesion of $\mathrm{DiI}^{+}$stained macrophages when comparing $4 \mathrm{R}$ and PEG/Eth groups (macrophages per DAPI, $0.12 \pm 0.015$, and $0.17 \pm 0.02$, respectively, mean \pm SEM) (Fig. 7B). As expected, incubation with LPS and PEG/Eth increased the adhesion of $\mathrm{DiI}^{+}$macrophages to hCMEC/D3 cells $(0.36 \pm 0.04$ macrophages/DAPI mean \pm SEM). The co-incubation of $4 \mathrm{R}$ with LPS significantly decreased the adhesion of macrophages compared with incubation of LPS with PEG/Eth (adhesion/DAPI, $0.23 \pm 0.03$, mean \pm SEM) (Fig. 7C), to a level similar to control conditions (control adhesion, $0.21 \pm 0.02$, mean \pm SEM).

\section{Discussion}

These studies demonstrate that $4 R$, a neuroprotective compound that easily crosses the BBB and accumulates in the brain, can be used as a lead compound for future anti-inflammatory therapy after an ischemic stroke. We have shown that $4 \mathrm{R}$ decreases macrophage adhesion to a cell model of the blood-brain barrier following inflammatory stimulation. 4R also downregulates NF-kB. Currently, there are no therapeutic measures that target the post-ischemic inflammatory response. However, several agents are under clinical studies, and some already licensed to treat other inflammatory diseases are being evaluated for their capability to reduce inflammation after brain ischemia.

After brain ischemia, the live neurons in the penumbra tissue suffer from deleterious signals, deteriorate, and die. The damaged or dead neurons release a series of inflammatory and death factors such as caspases and molecules, which change the microenvironment to initiate a local immune response from microglia 
and astrocytic cells. Local immunity will target the inflammatory insult via the production of more signaling molecules, phagocytosis, and the activation/recruitment of peripheral immunity [18-21]. Local inflammation induces a breakdown in the blood-brain barrier to permit peripheral leukocytes to migrate into the brain parenchyma. Primary macrophage and neutrophil infiltration commence a series of responses that contribute to a preliminary protective effect in the brain. However, studies have shown that prolonged activation of macrophages proves to be detrimental to the brain by the engulfment of healthy neurons $[22,23]$.

$4 \mathrm{R}$ is a natural cembranoid derived from the tobacco leaves and flower. It does not have a noxious effect when used in rats up to $98 \mathrm{mg} / \mathrm{kg}$ [16]. Olsson and colleagues (1993) tested the anti-inflammatory effect of $4 \mathrm{R}$ on the activity of cyclooxygenase type two (COX2) in seminal bovine vesicle microsomes [13]. A decrease in COX2 activity was produced by $4 \mathrm{R}$ at a concentration of $397 \mu \mathrm{M}$, considerably higher than the $\mathrm{EC}_{50}$ at $0.8 \mu \mathrm{M}$ at which $4 \mathrm{R}$ induces neuroprotection in ex vivo hippocampal slices $[24,25]$. In the present work, treatment with LPS and $4 \mathrm{R}$ at $1.53 \mu \mathrm{g} / \mathrm{mL}(5 \mu \mathrm{M})$ differentially regulated close to 400 genes related to canonical pathways from the cell cycle to inflammation. Microarray analysis determined that among the inflammatory canonical pathways, genes associated with the NF-kB signaling pathway were positively modulated by $4 \mathrm{R}$ treatment.

The NF-kB family is comprised of 5 subunits (RelA/p65, cRel, RelB, p50, p52), forming dimers that are generally inactive before post-translational modifications (PTM). The PTMs lead to conformational changes and detachment of inhibitor of kappa B proteins $(\mathrm{I} \kappa \mathrm{B} \alpha, \mathrm{IkB} \beta, \mathrm{IkB} \varepsilon, \mathrm{Bcl} 3$, and $\mathrm{IkB} \zeta)$, permitting nuclear translocation and transcriptional activity [26]. The NF-kB cascade transcribes genes for diverse cell functions ranging from apoptosis, proliferation, survival, adhesion, invasion, and inflammatory responses [27]. Among the dimers formed, the most abundant and 
directly related to inflammation is the p65/p50 subunit found in different cell types and hosts [26,28]. In this study, $4 \mathrm{R}$ treatment showed gene modulation that correlates with those transcribed by the p65/p50 dimer, the predominant dimer that mediates inflammation [29], and genes directly involved in the NF-kB pathway, such as the upregulation of the NFKB1 gene.

A.
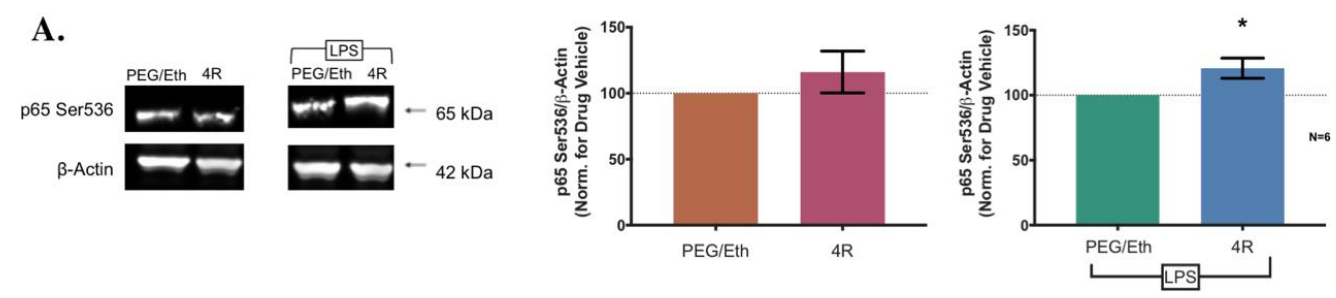

B.

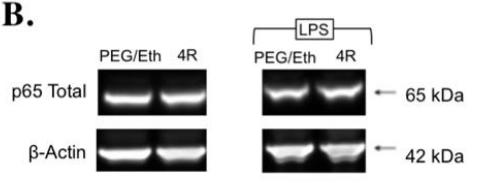

C.
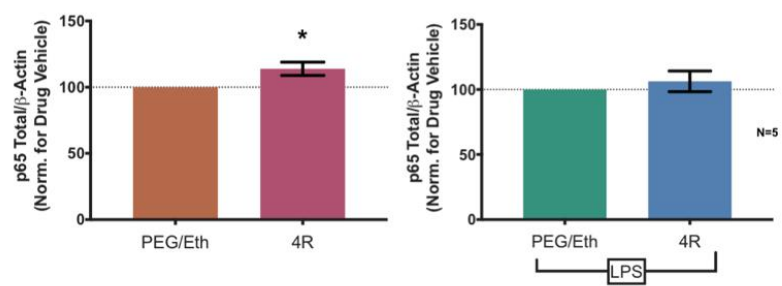

D.
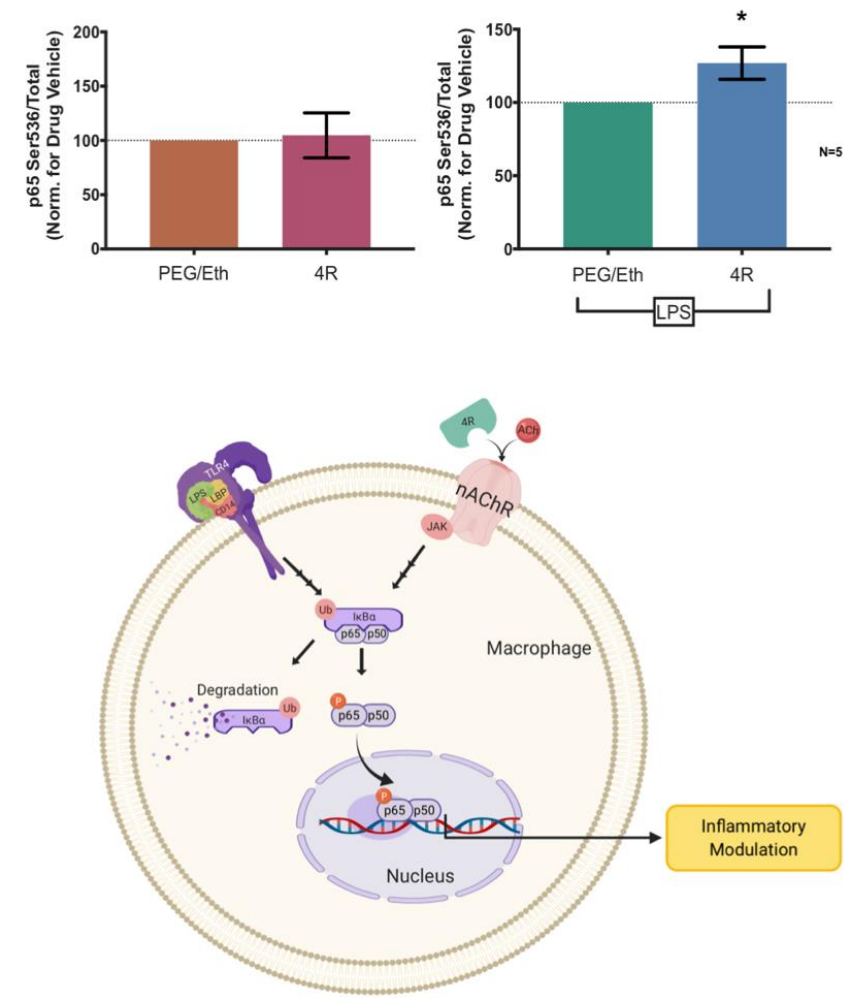

Figure 6. 1hr Treatment with $4 \mathrm{R}$ increased p65 phosphorylation at the serine 536 site, indicating an increase in NF-kB activation in macrophages. A. Expression of phosphorylated ser536 p65 under basal conditions and following co-incubation with LPS $+4 \mathrm{R}$ or vehicle (PEG/Eth) for $1 \mathrm{hr}$. ( $\mathrm{n}=6)$. B. Total p65 protein expression in macrophages treated with $4 \mathrm{R}$ or vehicle under basal or inflammatory conditions. C. The ratio of p65 ser536 to total p65 was increased by co-incubation with LPS and 4R, suggesting increased proportion of activated form ready for nuclear translocation. D. Diagram of a suggested mechanism of action for $4 R$ and LPS in macrophages resulting in cell response. Created with BioRender.com, figure exported under a paid subscription. Data represent the mean \pm SEM of 5-6 independent experiments. 


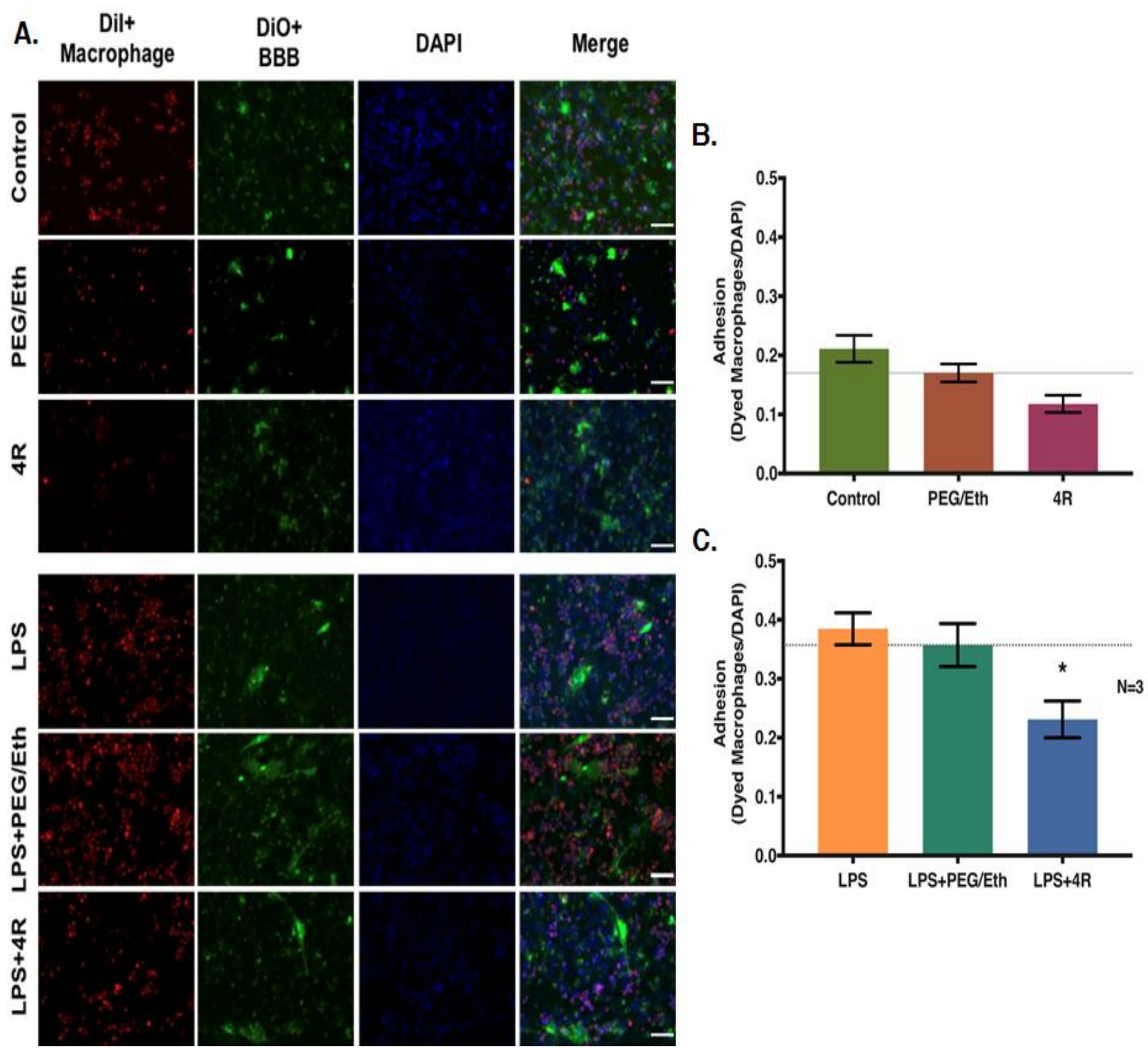

Figure 7. Post-inflammatory treatment of $4 R$ decreases overall macrophage adhesion to the $B B B$ after an inflammatory stimulus to the barrier. A. hCMEC/D3 cells were stained with DiO cells (green cells); macrophages were stained with DiI (red). All cell nuclei were labelled with DAPI, then images were merged to differentiate between free and macrophage-bound hCMEC/D3 cells. B. Under control conditions, adhesion of macrophages is detected, but $4 \mathrm{R}$ treatment does not reduce DiI+ macrophage adhesion. C. In LPS simulation groups, DiI+ macrophage adhesion increases when compared to control conditions. $4 \mathrm{R}$ treatment after inflammation induction with LPS reduces adhesion of macrophages to the BBB to a basal level (similar to PEG/Eth) when compared to both LPS and LPS+PEG/Eth group. One-Way ANOVA, Kruskal-Wallis test, with Dunn's multiple comparison test, ${ }^{*} \mathrm{p}<0.05$. 
The p50 homodimer does not possess the transcriptional capacity by itself due to the lack of the transactivation domain (TAD) in the p50 subunits, the domain that helps the dimer bind and transcribe the target DNA. Hence, studying the activation of the p65 subunit of the p50/p65 dimer correlates with the potential inflammatory role of 4R. There are a series of PTMs for the p65 subunit that leads to its activation and translocation to the nucleus; the most frequently studied is the phosphorylation of Ser536 in the TAD sequence. This phosphorylation serves as an indicator that the complex will translocate to the nucleus, leading to inflammatory gene transcription.

Under basal conditions, $4 \mathrm{R}$ treatment does not modulate the phosphorylation of the Ser536 of p65 in the times, and concentrations studied. The increase in phosphorylation on this site by LPS indicates the activation of p65. Although a onehour treatment with dexamethasone $(1 \mu \mathrm{M})$, is not enough to modulate LPSstimulate activation of p65 (data not shown), 4R treatment increases this activation when compared to the samples treated with the drug vehicle, PEG/Eth. The activation of the p65 protein occurs rapidly; however, the latent effect leads to the transcription of cytokines and chemokines that continue to modulate the inflammatory response of the macrophages.

Post-inflammatory $4 \mathrm{R}$ treatment upregulates genes involved in inflammatory responses of macrophages. However, this did not translate in damage propagation when using in vivo experiments previously published [9], suggesting that $4 \mathrm{R}$ modulates inflammation in a manner that provides additional immediate support, but not prolonged enough, validated by the adhesion of macrophages to the BBB. Inhibition of the NF-kB signaling cascade, inhibits the adhesion and chemoattraction of monocytes/macrophages [12], determining that any modulation of the NF-kB pathway will affect the infiltration of peripheral macrophages. However, the confirmed $4 \mathrm{R}$ treatment increase of p65 activated form, translates to a reduced 
adhesive capacity of macrophages to the BBB after an inflammatory insult, suggesting that $4 \mathrm{R}$ minimizes the invasion of macrophages to the CNS. Reducing the immune cells readily activated and providing a wave of inflammatory molecules could help the CNS restore homeostasis by not prolonging the inflammatory response in ischemic stroke. Direct neuroprotection by $4 \mathrm{R}$ in stroke provides an immediate benefit for the host [9], and now there is evidence that suggests that this protection can also include a decrease of inflammation.

Supplementary Materials: The following are available online at www.mdpi.com/xxx/s1, Figure S1: title, Table S1: title, Video S1: title.

\begin{tabular}{|l|c|c|c|c|c|c|c|c|c|}
\cline { 2 - 10 } \multicolumn{1}{c|}{} & \multicolumn{8}{c|}{ CT (Mean \pm SEM) } \\
\hline Samples & GAPDH & UL-1Beta & NFKBIE & ITGB5 & NFKB1 & CCL5 & iCAM1 & MCP1 & INOS \\
\hline PEG/Eth & $12.54 \pm 0.3384$ & $29.29 \pm 0.4844$ & $22.78 \pm 0.3378$ & $23.3 \pm 0.8646$ & $21.64 \pm 0.7482$ & $26.89 \pm 1.57$ & $22.87 \pm 1.215$ & $22.79 \pm 1.223$ & $31.41 \pm 0.547$ \\
\hline AR & $12.92 \pm 0.435$ & $29.24 \pm 0.5143$ & $22.96 \pm 0.2215$ & $23.77 \pm 1.009$ & $22.29 \pm 0.9952$ & $27.58 \pm 1.853$ & $23.23 \pm 1.378$ & $23.26 \pm 1.267$ & $30.98 \pm 0.4795$ \\
\hline LPS+PEG/Eth & $12.72 \pm 0.3662$ & $15.65 \pm 0.07586$ & $21.14 \pm 0.3131$ & $25.34 \pm 1.002$ & $19.54 \pm 0.8916$ & $16.61 \pm 1.191$ & $20.79 \pm 1.101$ & $16.97 \pm 0.9341$ & $21.54 \pm 0.71$ \\
\hline LPS+4R & $12.83 \pm 0.3995$ & $15.8 \pm 0.2754$ & $21.46 \pm 0.2718$ & $25.81 \pm 0.9355$ & $20.12 \pm 0.7977$ & $16.92 \pm 1.428$ & $21.22 \pm 1.397$ & $16.8 \pm 0.9531$ & $22.19 \pm 0.3698$ \\
\hline
\end{tabular}

Table S1. $\mathrm{C}_{\mathrm{T}}$ values (mean $\pm \mathrm{SEM}$ ) of microarray treated samples for gene validation. GAPDH $\mathrm{C}_{\mathrm{T}}$ values are constant between all samples. For genes IL1B, NFKBIE, NFKB1, CCL5, ICAM1, MCP1 and INOS it shows a lower $C_{T}$ value for samples treated with LPS when compared to basal conditions. However, for ITGB5, LPS treatment decreases the $\mathrm{C}_{\mathrm{T}}$ values when compared to drug treated basal conditions.

\begin{tabular}{|c|c|c|c|c|c|c|c|c|c|}
\hline & \multicolumn{9}{|c|}{ CT (Mean \pm SEM) } \\
\hline Samples & GAPDH & |l-1Beta & NFKBIE & ITGBS & NFKB1 & $\mathrm{CCl} 5$ & iCAM1 & MCP.1 & iNOS \\
\hline PEG/Eth & $14.68 \pm 0.4803$ & $30.52 \pm 0.3371$ & 24.111.1.121 & $26.29 \pm 2.039$ & $25.55+3.009$ & $27.88 \pm 0.8746$ & $25.32 \pm 1.406$ & $23.51 \pm 0.8612$ & $31.99+1.264$ \\
\hline $4 R$ & $15.06 \pm 0.7734$ & 31.35t0.7224 & $24.57 \pm 1.339$ & $26.86 \pm 2.011$ & $26.98+3.919$ & $28.16 \pm 1.202$ & $26.03 \pm 1.81$ & $23.88 \pm 1.293$ & 32.11+1.,377 \\
\hline LPS+PEG/Eth & $14.62 \pm 0.2553$ & 17.83t1.023 & $22.99 \pm 0.4001$ & 26.31+0.1201 & $21.85 \pm 2.123$ & $16.88 \pm 0.2867$ & $22.16 \pm 0.5895$ & $16.46 \pm 0.7704$ & $20.42 \pm 0.6021$ \\
\hline LPS+AR & $13.9 \pm 0.4231$ & $17.75 \pm 1.39$ & $22.68 \pm 0.06882$ & $26.14 \pm 0.4742$ & $21.86 \pm 2.386$ & $16.49 \pm 0.05655$ & $22.11 \pm 0.3039$ & $15.78 \pm 0.697$ & $19.9 \pm 0.5459$ \\
\hline
\end{tabular}


Table S2. C $\mathrm{T}$ values (mean $\pm \mathrm{SEM}$ ) of $6 \mathrm{hrs}$ continued drug with or without LPS treatment to compares gene expression to microarray timeline. GAPDH $\mathrm{C}_{\mathrm{T}}$ values are within a range for all samples. The $\mathrm{C}_{\mathrm{T}}$ values for the ITGB5 gene is not altered by LPS treatment when compared to basal conditions drug treated. For IL1B, NKFBIE, NFKB1, CCL5, ICAM1, MCP1, and INOS, basal conditions show a higher $C_{T}$ value, and LPS treatment lowers the $C_{T}$ value needed to surpass the threshold established.

Conceptualization, Maxine N. Gonzalez-Vega, Vesna A. Eterovic, Pedro A. Ferchmin, and Antonio Henrique Martins; Formal analysis, Maxine N. GonzalezVega; Funding acquisition, Pedro A. Ferchmin, and Antonio Henrique Martins; Methodology, Maxine N. Gonzalez-Vega, Sandeep Sreerama, and Antonio Henrique Martins; Project administration, Kiminobu Sugaya, Pedro A. Ferchmin, and Antonio Henrique Martins; Resources, Kiminobu Sugaya, and Antonio Henrique Martins; Supervision, Antonio Henrique Martins; Validation, Maxine N. Gonzalez-Vega, Kelvin Carrasquillo-Carrion, and Abiel Roche-Lima; Visualization, Maxine N. Gonzalez-Vega; Writing - original draft, Maxine N. Gonzalez-Vega; Writing - review \& editing, Susan Corey Best, Kiminobu Sugaya, Vesna A. Eterovic, Pedro A. Ferchmin, and Antonio Henrique Martins.

Funding: “This research was funded by Institutional Development Award (IDeA) from the National Institute of General Medical Sciences of the National Institutes of Health under grant number P20 GM103475-15 (AHM); SNRP U54 NS039408 (AHM, MGV), RCMI grant U54 MD007600 (AHM).

Acknowledgments: We would like to acknowledge Michelle MartinezMontemayor, Ph.D. Department of Biochemistry, University Central del Caribe for her critical reading of the manuscript and advice during this project.

Conflicts of Interest: The authors declare no conflict of interest.

\section{References}

1. Young, M.J.; Regenhardt, R.W.; Leslie-Mazwi, T.M.; Stein, M.A. Disabling stroke in persons already with a disability: Ethical dimensions and directives. Neurology 2020.

2. Lai, T.W.; Zhang, S.; Wang, Y.T. Excitotoxicity, and stroke: identifying novel targets for neuroprotection. Prog Neurobiol 2014, 115, 157-188.

3. Chamorro, A.; Dirnagl, U.; Urra, X.; Planas, A.M. Neuroprotection in acute 
stroke: targeting excitotoxicity, oxidative and nitrosative stress, and inflammation. Lancet Neurol 2016, 15, 869-881.

4. Castillo, J.; Davalos, A.; Noya, M. Progression of ischaemic stroke and excitotoxic aminoacids. Lancet 1997, 349, 79-83.

5. Hazell, A.S. Excitotoxic mechanisms in stroke: an update of concepts and treatment strategies. Neurochem Int 2007, 50, 941-953.

6. Atri, C.; Guerfali, F.Z.; Laouini, D. Role of Human Macrophage Polarization in Inflammation during Infectious Diseases. Int J Mol Sci 2018, 19.

7. Cronkite, D.A.; Strutt, T.M. The Regulation of Inflammation by Innate and Adaptive Lymphocytes. J Immunol Res 2018, 2018, 1467538.

8. Cao, S.; Zhang, X.; Edwards, J.P.; Mosser, D.M. NF-kappaB1 (p50) homodimers differentially regulate pro- and anti-inflammatory cytokines in macrophages. J Biol Chem 2006, 281, 26041-26050.

9. Martins, A.H.; Hu, J.; Xu, Z.; Mu, C.; Alvarez, P.; Ford, B.D.; El Sayed, K.; Eterovic, V.A.; Ferchmin, P.A.; Hao, J. Neuroprotective activity of (1S,2E,4R,6R,-7E,11E)-2,7,11-cembratriene-4,6-diol (4R) in vitro and in vivo in rodent models of brain ischemia. Neuroscience 2015, 291, 250-9.

10. Hu, J.; Ferchmin, P.A.; Hemmerle, A.M.; Seroogy, K.B.; Eterovic, V.A.; Hao, J. 4R-Cembranoid Improves Outcomes after 6-Hydroxydopamine Challenge in Both In vitro and In vivo Models of Parkinson's Disease. Front Neurosci 2017, 11, 272.

11. Ferchmin, P.A.; Hao, J.; Perez, D.; Penzo, M.; Maldonado, H.M.; Gonzalez, M.T.; Rodriguez, A.D.; de Vellis, J. Tobacco cembranoids protect the function of acute hippocampal slices against NMDA by a mechanism mediated by alpha4beta2 nicotinic receptors. J Neurosci Res 2005, 82, 631-641.

12. Li, K.; Li, J.; Zheng, J.; Qin, S. Reactive Astrocytes in Neurodegenerative Diseases. Aging Dis 2019, 10, 664-675.

13. Olsson, E.; Holth, A.; Kumlin, E.; Bohlin, L.; Wahlberg, I. Structure-related inhibiting activity of some tobacco cembranoids on the prostaglandin synthesis in vitro. Planta Med 1993, 59, 293-295.

14. Ferchmin, P.A.; Andino, M.; Reyes Salaman, R.; Alves, J.; Velez-Roman, J.; Cuadrado, B.; Carrasco, M.; Torres-Rivera, W.; Segarra, A.; Martins, A.H.; et al. 4R-cembranoid protects against diisopropylfluorophosphate-mediated 
neurodegeneration. Neurotoxicology 2014, 44, 80-90.

15. Ferchmin, P.A.; Perez, D.; Cuadrado, B.L.; Carrasco, M.; Martins, A.H.; Eterovic, V.A. Neuroprotection Against Diisopropylfluorophosphate in Acute Hippocampal Slices. Neurochem Res 2015, 40, 2143-2151.

16. Velez-Carrasco, W.; Green, C.E.; Catz, P.; Furimsky, A.; O'Loughlin, K.; Eterovic, V.A.; Ferchmin, P.A. Pharmacokinetics and Metabolism of 4RCembranoid. PLoS One 2015, 10, e0121540.

17. Pachter, J.S.; De Vries, H.E.; Fabry, Z. The blood-brain barrier and its role in immune privilege in the central nervous system. J. Neuropathol. Exp. Neurol. 2003.

18. Chamorro, A.; Meisel, A.; Planas, A.M.; Urra, X.; van de Beek, D.; Veltkamp, R. The immunology of acute stroke. Nat Rev Neurol 2012, 8, 401-410.

19. Kamel, H.; Iadecola, C. Brain-immune interactions and ischemic stroke: clinical implications. Arch Neurol 2012, 69, 576-581.

20. del Zoppo, G.J.; Becker, K.J.; Hallenbeck, J.M. Inflammation after stroke: is it harmful? Arch Neurol 2001, 58, 669-672.

21. Yenari, M.A.; Kauppinen, T.M.; Swanson, R.A. Microglial activation in stroke: therapeutic targets. Neurotherapeutics 2010, 7, 378-391.

22. Neher, J.J.; Emmrich, J. V; Fricker, M.; Mander, P.K.; Thery, C.; Brown, G.C. Phagocytosis executes delayed neuronal death after focal brain ischemia. Proc Natl Acad Sci U S A 2013, 110, E4098-107.

23. Neher, J.J.; Neniskyte, U.; Brown, G.C. Primary phagocytosis of neurons by inflamed microglia: potential roles in neurodegeneration. Front Pharmacol 2012, $3,27$.

24. Eterovic, V.A.; Perez, D.; Martins, A.H.; Cuadrado, B.L.; Carrasco, M.; Ferchmin, P.A. A cembranoid protects acute hippocampal slices against paraoxon neurotoxicity. Toxicol Vitr. 2011, 25, 1468-1474.

25. Yan, N.; Du, Y.; Liu, X.; Zhang, H.; Liu, Y.; Zhang, Z. A Review on Bioactivities of Tobacco Cembranoid Diterpenes. Biomolecules 2019, 9.

26. Cookson, V.J.; Chapman, N.R. NF-kappaB function in the human myometrium during pregnancy and parturition. Histol Histopathol 2010, 25, 945-956. 
27. Liu, T.; Zhang, L.; Joo, D.; Sun, S.C. NF-kappaB signaling in inflammation. Signal Transduct Target Ther 2017, 2.

28. Oeckinghaus, A.; Ghosh, S. The NF-kappaB family of transcription factors and its regulation. Cold Spring Harb Perspect Biol 2009, 1, a000034.

29. Lin, L.; DeMartino, G.N.; Greene, W.C. Cotranslational dimerization of the Rel homology domain of NF-kappaB1 generates p50-p105 heterodimers and is required for effective p50 production. EMBO J 2000, 19, 4712-4722. 